\title{
TSDC Analysis on Nylon 66 Films with Different End Group Balance in View of Water Influence
}

\author{
Kazuishi SATO, ${ }^{1, \dagger}$ Toshinori KoIzumI, ${ }^{2}$ and Kunihiko OKAJIMA ${ }^{1}$ \\ ${ }^{1}$ Faculty of Engineering, Tokushima Bunri University, 1314-1 Shido, Sanuki 769-2193, Japan \\ ${ }^{2}$ Central Research Laboratories, $R$ \& D Division, Asahi-Kasei Corporation, 1-2 Samejima, Fuji 416-8501, Japan
}

(Received May 24, 2004; Accepted November 2, 2004; Published March 15, 2005)

\begin{abstract}
TSDC analysis of nylon with different balance of end groups ( $f_{\mathrm{N}}$; amino group fraction) confirms the existence of $\alpha_{\rho}, \alpha, \beta$ and $\gamma$ relaxations. We found a well resolved $\alpha_{\rho}$ relaxation previously detected only as a strong upswing by mechanical relaxation analysis and that two distinct relaxations for nylon rich in carboxyl end groups appear in that region. Two different relaxation mechanisms each for $\alpha$ and $\beta$ relaxations were found. The former tend to merge into a single mechanism as $f_{\mathrm{N}}$ increases, and with the presence of water in polymer, the two relaxation mechanisms merge into a single mechanism for $\alpha$ and $\beta$ relaxations. Even in the presence of water, the $\alpha$ relaxation for nylon rich in carboxyl end groups still follows two different mechanisms. Study on the interaction of water with the polymer confirmed that the molecular chains in the amorphous region of nylon 66 rich in amino end groups show strong mutual interaction, hence exhibiting stability against water attack. [DOI 10.1295/polymj.37.137]

KEY WORDS TSDC / Nylon 66 Films / End Group Balance / Carboxyl End Group / Water /

Relaxation /
\end{abstract}

Voluminous studies of the mechanical relaxation behavior of polyamides have been made with special emphasis on the effects of water in the polymer. ${ }^{1-19}$ For poly(hexamethylene-adipamide) (nylon 66), three loss peaks at about $-120,-50$ to -40 and $65-80{ }^{\circ} \mathrm{C}$, and an upswing in the higher temperature region are well recognized. ${ }^{1-6}$ These are conventionally referred to as $\gamma, \beta, \alpha^{\prime}$ and $\alpha$ relaxations, respectively. The considerable effect of water on the loss peaks for nylon 66 appears to have been first reported by Deeley et al. ${ }^{2}$ and Lacson $e t a l .^{3}$ The $\beta$ peak disappears upon complete drying of nylon $66,{ }^{2}$ and the $\alpha^{\prime}$ peak shifts towards lower temperatures and the $\gamma$ peak decreases with an increase of water content in the polymer. ${ }^{3} \mathrm{~A}$ more systematic study was carried out by Woodward et al. on nylon 66 rods with number-average molecular weight $M_{\mathrm{n}}=15,800$, density $\rho=1.145 \mathrm{~g} / \mathrm{cm}^{3}$ and crystallinity, determined by X-ray diffraction, $\chi_{\mathrm{c}}=$ $54 \%$ in the water content range of $0-6.4 \mathrm{wt} \% .^{5}$ They found that with increase in water content 1) the loss peak temperature for the $\alpha^{\prime}$ relaxation shifts down to ca. $0{ }^{\circ} \mathrm{C}, 2$ ) the $\beta$ relaxation appears at a water content of $0.9 \mathrm{wt} \%$, accompanied by increase in the storage modulus in the temperature region of $c a$. -120 to $-20^{\circ} \mathrm{C}$ and 3) the loss peak and the associated modulus related to the $\gamma$ relaxation decrease. Based on the above experimental results they propose that the $\alpha^{\prime}$ relaxation is associated with segmental motion caused by the breaking of hydrogen bond in the amorphous region, the $\beta$ relaxation is attributable to segmental motion involving methylene and neighboring nonbonded amide groups and the $\gamma$ relaxation corresponds to segmental motion of the small amount of methylene associated with amide groups. This assignment of the $\alpha^{\prime}$ relaxation is supported by a dielectric loss measurement made by Boyel. ${ }^{7}$ Thus, the relaxation behavior of nylon 66 or 6 seems to have been settled already. However, when dealing with the effect of water in the polymer, all authors have ignored the possible effects of the terminal groups (amino end group and carboxyl end group). The present authors have pointed out the importance of the balance of terminal groups of poly(hexamethylene adipamide) (nylon 66) (for example, the molar fraction $f_{\mathrm{N}}$ of amino end group) to the water adsorption behavior, rheological and thermal properties and crystallization kinetics of the polymers, ${ }^{20}$ fiber structure formation during the melt-spinning process ${ }^{21}$ and hydrogen bond strength, probably related to the ionization of water in the polymer. ${ }^{22}$ All these results support the idea that nylon 66 with high $f_{\mathrm{N}}$ has inherently stronger molecular interaction in the amorphous region, hindering structural change induced by heat and humidity to some extent, due to the alkaline nature of water in the polymer. ${ }^{22}$ The authors also confirmed from ${ }^{1} \mathrm{H}$ longitudinal relaxation $T_{1}$ measurements that at least two kinds of water exist in the polymer, of which mobility of which mobility depends on $f_{\mathrm{N}} .{ }^{22}$ This situation leads to an interest in investigating the relaxation behavior of nylon 66 with respect to $f_{\mathrm{N}}$.

${ }^{\dagger}$ To whom correspondence should be addressed (ksato@fe.bunri-u.ac.jp). 
Thermally stimulated current (TSDC) analysis has been widely used to investigate relaxation in various polymers ${ }^{23}$ and its technical advance has made it possible to detect a depolarized current as low as $10^{-17} \mathrm{~A}$ from the meta-stable exited state of the polymer, resulting from the imposition of a direct current voltage. This enables us to examine the very fine structure in the higher order of super-molecular structure. The equivalent frequency of the TSDC method is $10^{-3}$ $10^{-4} \mathrm{~Hz}$, which is somewhat lower than for mechanical relaxation techniques and dielectric measurements, enabling us to detect longer relaxation characteristic of polymer solids. Moreover, the thermal window technique for the TSDC method by Bucci-FieschiGuidi $^{24}$ allows us to separate elementary spectra from units having widely distributed relaxations, giving information on the distribution of relaxation times, temperature dependence and other basic physical quantities. This technique is preferably applied to dipolar polymers such as polyamide. Note that TSDC curves for nylon 66 were reported by Vanderschueren and Linkens ${ }^{25}$ but no new understanding was gained despite the advantages of this technique.

This paper discusses relaxation appearing in the TSDC results in view of the effect of water in nylon 66 , with special emphasis on the $f_{\mathrm{N}}$ of the polymers. The object is to clarify the relationship between solid structural changes and interactions of water and $f_{\mathrm{N}}$.

\section{EXPERIMENTAL}

\section{Nylon 66 Films with Different $f_{N}$}

Three nylon 66 chips differing in $f_{\mathrm{N}}$ (manufactured by Asahi Chemicals Co., Ltd., Japan) were separately extruded into water baths to reform the chips using a twin screw-extruder (Labo Plastomill, Toyo Seiki Seisaku-sho Co., Ltd., Japan) under the following conditions to delete the thermal history imposed on each chip: Cylinder temperature; $283^{\circ} \mathrm{C}$, die temperature $290^{\circ} \mathrm{C}$, screw revolution; $70 \mathrm{rpm}$, feeding rate; 30 rpm, extruding volume; $50 \mathrm{~g} / \mathrm{min}$.

The chips thus obtained were subjected to heatpressing $\left(50 \mathrm{~kg} / \mathrm{cm}^{2}\right.$ at $290{ }^{\circ} \mathrm{C}$ for $\left.3 \mathrm{~min}\right)$ to give films with a thickness of $0.08 \mathrm{~mm}$, using a press-forming apparatus (Model AYSR-5, Kanefuji Kinzoku Co., Ltd., Japan). The concentrations of terminal groups were determined by a procedure described previously, ${ }^{1}$ and $f_{\mathrm{N}}$ (= number of amino end group/total numbers of amino and carboxyl end groups) and $M_{\mathrm{n}}$ were calculated and are listed in Table I. The films were conditioned at $20^{\circ} \mathrm{C}$ and $\mathrm{RH}=65 \%$ for $7 \mathrm{~d}$ before being used for any experiments. All films had water content of $1.52( \pm 0.02) \mathrm{wt} \%$, as determined by the Carl-Fisher method (KF-06, VA-06, Mitsubishi Kasei Co., Ltd.).
Table I. Characteristics of Nylon 66 film with different balance of end groups $\left(f_{\mathrm{N}}\right)$

\begin{tabular}{ccccc}
\hline & $\begin{array}{c}f_{\mathrm{N}}{ }^{\mathrm{a}} \\
(-)\end{array}$ & $\begin{array}{c}\mathrm{NH}_{2} \\
(\mathrm{meq} / \mathrm{kg})\end{array}$ & $\begin{array}{c}\mathrm{COOH} \\
(\mathrm{meq} / \mathrm{kg})\end{array}$ & $\begin{array}{c}\mathrm{Mn}^{\mathrm{b}} \\
(-)\end{array}$ \\
\hline $\mathrm{A}$ & $\mathbf{0 . 6 2}$ & 75.9 & 46.7 & $1.63 \times 10^{4}$ \\
$\mathrm{~B}$ & $\mathbf{0 . 4 8}$ & 52.9 & 57.5 & $1.81 \times 10^{4}$ \\
$\mathrm{C}$ & $\mathbf{0 . 3 6}$ & 45.8 & 80.1 & $1.59 \times 10^{4}$ \\
\hline
\end{tabular}

${ }^{\mathrm{a}} f_{\mathrm{N}}=\left[\mathrm{NH}_{2}\right] /\left(\left[\mathrm{NH}_{2}\right]+[\mathrm{COOH}]\right){ }^{\mathrm{b}} M_{\mathrm{n}}=2 \times 10^{6} /\left(\left[\mathrm{NH}_{2}\right]+\right.$ $[\mathrm{COOH}])$

\section{Thermally Stimulated Current (TSC) Analysis}

TSC measurements were made using a TSC/RMA spectrometer 91000 (Rigaku/Solomat) with the film sample aligned between the electrodes in the sample chamber, which was flooded with $\mathrm{He}$ gas. Global and thermal window measurements were carried out as follows:

Global Measurements. Polymer samples were polarized at a given polarizing temperature $T_{\mathrm{p}}\left(=75^{\circ} \mathrm{C}\right)$ by imposing a polarizing voltage $V_{\mathrm{p}}(=1800 \mathrm{~V} / \mathrm{mm})$ for a given polarizing time $t_{\mathrm{p}}(=2 \mathrm{~min})$ and the samples were frozen to $-150^{\circ} \mathrm{C}$ while under $V_{\mathrm{p}}$ so as to quench the polarized state of the polymer molecules. Subsequently, the depolarization of samples was carried out at a depolarizing temperature $T_{\mathrm{d}}\left(=-150^{\circ} \mathrm{C}\right)$ for a depolarizing time $t_{\mathrm{d}}(=2 \mathrm{~min})$ and the samples were heated at a rate of $7^{\circ} \mathrm{C} / \mathrm{min}$. The TSC curve (depolarized current $J v s$. temperature $T$ curve) was obtained by recording the current, $J$, generated during heating.

Thermal Window Measurements. This technique polarizes a particular molecular state and measure relaxation time within an overall polarizing mechanism which has some distribution of relaxation times. In the present experiment, the polarizing temperature range $\left(\Delta T=T_{\mathrm{p}}-T_{\mathrm{d}}\right)$ was set to $2^{\circ} \mathrm{C}$. Under $V_{\mathrm{p}}(=1800$ $\mathrm{V} / \mathrm{mm}$ ) the polarization at $T_{\mathrm{p}}$ was made for $2 \mathrm{~min}$ and the sample was depolarized at $T_{\mathrm{d}}=T_{\mathrm{p}}-2{ }^{\circ} \mathrm{C}$ for $t_{\mathrm{d}}=2 \mathrm{~min}$. After this time, the majority of the dipolar molecules having a relaxation time less than 2 min was deemed to be depolarized. Then the sample was further cooled to $T_{\mathrm{p}}-50^{\circ} \mathrm{C}$ so that the remaining polarized moiety was frozen, and the TSC curve was obtained by heating to $T_{\mathrm{p}}+50^{\circ} \mathrm{C}$ at a heating rate of $7{ }^{\circ} \mathrm{C} / \mathrm{min}$. These procedures were performed at $5^{\circ} \mathrm{C}$ intervals between $T_{\mathrm{p}}=-50$ to $80^{\circ} \mathrm{C}$ in order to obtain a relaxation map showing the unique relaxation mechanism.

Analytical Procedure. Usually the temperature evolution of the relaxation times can be well approximated by the Arrhenius equation:

$$
\tau(T)=\tau_{0} \exp \left(E_{\mathrm{a}} / k T\right)
$$

where $\tau_{0}$ is a preexponential factor, $k$ is Boltzmann's 
constant, and $E_{\mathrm{a}}$ is the apparent activation energy for the process.

If the logarithm of the preexponential factor $\tau_{0}$ varies linearly with activation energy $E_{\mathrm{a}}$, as is often experimentally found for polymeric solids, one observes a compensation law:

$$
\tau_{0}=\tau_{\mathrm{c}} \exp \left(-E_{\mathrm{a}} / k T_{\mathrm{c}}\right) .
$$

Then, expression (3) becomes

$$
\tau(T)=\tau_{\mathrm{c}} \exp \left[\frac{E_{\mathrm{a}}}{k}\left(\frac{1}{T}-\frac{1}{T_{\mathrm{c}}}\right)\right],
$$

where $\tau_{\mathrm{c}}$ and $T_{\mathrm{c}}$ are phenomenological parameters, known as the compensation time and compensation temperature, respectively.

Simulation of dielectric spectra using the relaxation parameters derived from TSDC experiments can be carried out for a system with distributed relaxation times as follows: ${ }^{26}$

$$
\begin{aligned}
\varepsilon^{\prime} & =\varepsilon_{\infty}+\sum_{i=1}^{n}\left(\varepsilon_{\mathrm{s}}-\varepsilon_{\infty}\right)_{i} \frac{1}{1+\omega^{2} \tau_{i}^{2}(T)} \\
\varepsilon^{\prime \prime} & =\sum_{i=1}^{n}\left(\varepsilon_{\mathrm{s}}-\varepsilon_{\infty}\right)_{i} \frac{\omega \tau_{i}(T)}{1+\omega^{2} \tau_{i}^{2}(T)}
\end{aligned}
$$

where $\varepsilon^{\prime}$ and $\varepsilon^{\prime \prime}$ are the real and imaginary parts of a complex dielectric constant, $\varepsilon_{\mathrm{s}}$ and $\varepsilon_{\infty}$ are the staticand infinite-frequency dielectric constants respectively, $\omega$ is the angular frequency, and $\tau_{i}(T)$ is the Debye relaxation time for system $i$ in which temperature dependence is governed by the compensation law given by

$$
\tau_{i}(T)=\tau_{\mathrm{c} i} \exp \left[\frac{E_{\mathrm{a} i}}{k}\left(\frac{1}{T}-\frac{1}{T_{\mathrm{c} i}}\right)\right],
$$

where the parameters $\left(\varepsilon_{\mathrm{s}}-\varepsilon_{\infty}\right)_{i}$ and $\tau_{i}(T)$ are taken from subsequent thermal sampling technique experiments. ${ }^{27}$ The dielectric strength for system $i, \Delta \varepsilon_{i}=$ $\left(\varepsilon_{\mathrm{S}}-\varepsilon_{\infty}\right)_{I}$, was estimated from the total charge released in $i$-th thermal sampling experiment:

$$
\Delta \varepsilon_{i}=\frac{1}{F \varepsilon_{0}} \int_{t_{0}}^{\infty} J(t) \mathrm{d} t=\frac{1}{F \varepsilon_{0} \beta} \int_{T_{0}}^{T_{\infty}} J(T) \mathrm{d} T,
$$

where $F$ is the field strength and $\varepsilon_{0}$ is the dielectric constant of free space; $\beta$ is the heating rate and $J(T)$ is the current density of the thermal sampling spectrum at temperature $T$.

The relaxation time can be described by the absolute rate theory equation as follows: ${ }^{28}$

$$
\tau(T)=\frac{h}{k T} \exp \left(\frac{-\Delta S^{*}}{k}\right) \exp \left(\frac{\Delta H^{*}}{k T}\right),
$$

where $\Delta S^{*}, \Delta H^{*}$ are activation entropy and enthalpy,

At the compensation temperature $T_{\mathrm{c}}$, the above equations are reduced to:

$$
\frac{\Delta S^{*}}{k}=\ln \frac{h}{k T_{\mathrm{c}}}-\ln \tau_{\mathrm{c}}+\frac{\Delta H^{*}}{k T_{\mathrm{c}}},
$$

Estimated $\Delta H^{*}$ and $\Delta S^{*}$ at compensation temperature $T_{\mathrm{c}}$ can be applied to thermal expansion or self-diffusional processes of polymers as follows:

$$
\begin{aligned}
& \Delta H^{*}=\frac{1}{9 \Delta \alpha} \Delta S^{*}+\Delta H_{\mathrm{tor}}^{*}, \\
& T_{\mathrm{c}}=\frac{1}{9 \Delta \alpha},
\end{aligned}
$$

$\Delta H_{\text {tor }}^{*}$ is the internal torsional energy of the polymer solid and $\Delta \alpha$ is the isobaric coefficient of thermal expansion between the rubbery and glassy states.

\section{RESULTS AND DISCUSSION}

Figures $1 \mathrm{a}$ and $\mathrm{b}$ show the global current amplitude $(J)$-temperature $(T)$ curves in the $\alpha, \beta$ and $\gamma$ relaxation regions for nylon 66 films with different $f_{\mathrm{N}}$ and with practically no water content. In Figure 1a, peaks are observed at around $60,-80$ and $-135^{\circ} \mathrm{C}$, and a strong upswing are observed at temperatures higher than $80^{\circ} \mathrm{C}$. We refer to them here as the $\alpha_{\rho}$ (corresponding to $\alpha$ for mechanical relaxation), $\alpha$ (corresponding to $\alpha^{\prime}$ for mechanical relaxation), $\beta$ and $\gamma$ relaxations from high to low temperatures respectively. The $J$-axis expanded profiles (Figure 1b) clearly resolve the upswing $\left(\alpha_{\rho}\right)$. Nylon 66 with $f_{\mathrm{N}}=0.36$ gives rise to two relaxations at $c a .105$ and $82^{\circ} \mathrm{C}$ and other two nylon 66's have a single peak at $c a$. $90^{\circ} \mathrm{C}$. Judging from the half value widths of $\alpha_{\rho}$, nylon 66 with the highest $f_{\mathrm{N}}$ has the strongest molecular association density. The relaxation inevitably expresses the dominance of Brownian motion in the strongly hydrogen bonded region. It is not clear at present why the nylon 66 with lower $f_{\mathrm{N}}=0.36$ gives rise to two separate relaxations in this region. All these relaxations are found at $c a .20^{\circ} \mathrm{C}$ lower than those observed by mechanical relaxation analysis. When the peak separation method is utilized, some shoulder peaks are found on the higher temperature side of the $\alpha_{\rho}$ and $\beta$ relaxations and on the lower temperature side of the $\alpha$ relaxation. Obviously, each $J$ value becomes smaller for nylon 66 as $f_{\mathrm{N}}$ increases. This means that segmental motion in the segmental domains corresponding to these relaxations is relatively restricted or that such a region is far smaller for nylon 66 with increased $f_{\mathrm{N}}$.

The $J-T$ curves for polymers with $1.52( \pm 0.02)$ wt $\%$ water are shown in Figures $2 \mathrm{a}$ and $\mathrm{b}$. For all samples the $\alpha$ peak is shifted to $c a .0{ }^{\circ} \mathrm{C}$ and $J$ increases as $f_{\mathrm{N}}$ decreases. $J$ is larger than for samples with practically no water. This indicates that the $\alpha$ relaxation reflects some inherent characteristic associated 


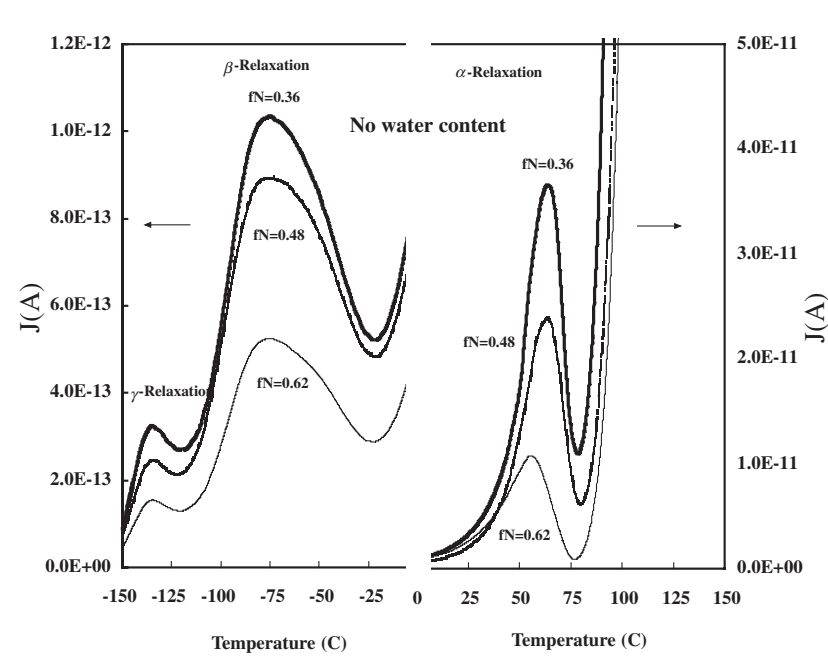

(a)

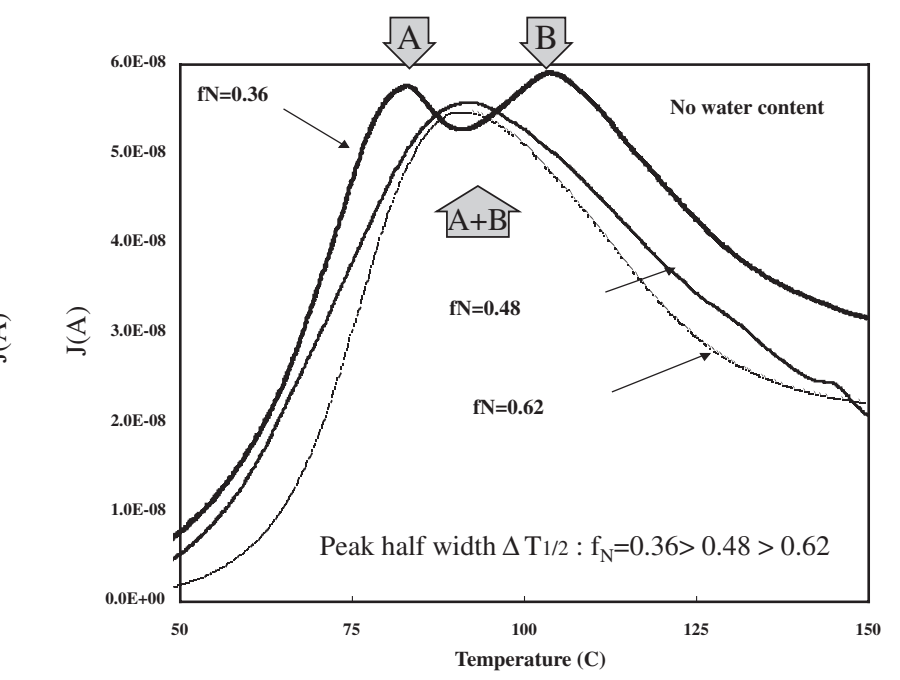

(b)

Figure 1. (a) Global TSDC spectra corresponding to the $\alpha, \beta, \gamma$-relaxation of Nylon 66 with different balance of end groups $\left(f_{\mathrm{N}}\right)$. (b) $\alpha_{\rho}$-relaxation related to electronic conduction in the amorphous region of Nylon 66.

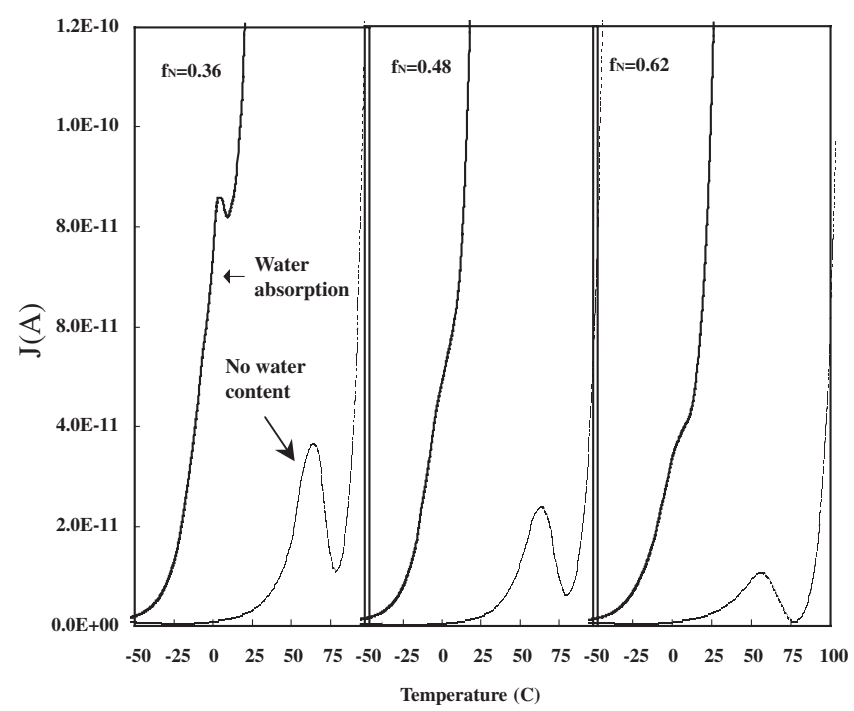

(a)

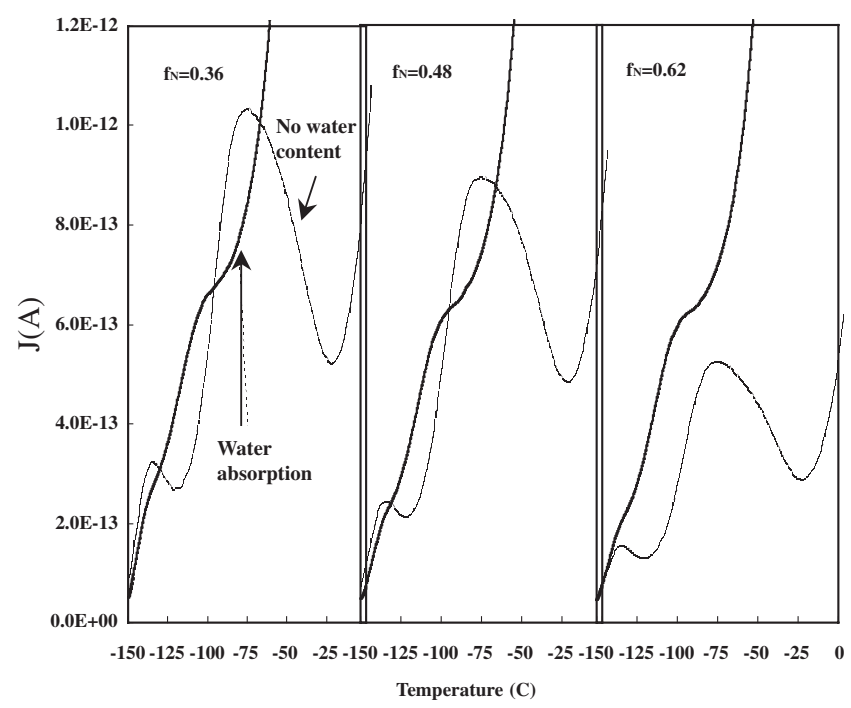

(b)

Figure 2. Global TSDC spectra corresponding to the $\alpha, \beta, \gamma$-relaxations of Nylon 66 with different $f_{\mathrm{N}}$ values.

with $f_{\mathrm{N}}$ and is closely related to the presence of water which might considerably disrupt hydrogen bonding. If $J$ reflects the amount of hydrogen bonding, nylon 66 with higher $f_{\mathrm{N}}$ will be relatively stable against water attack, as has been pointed out previously. ${ }^{22}$ The $\beta$ relaxation peak also shifts to the lower temperature side but its $J$ value seems to be almost the same irrespective of $f_{\mathrm{N}}$. (It is slightly larger for nylon 66 with lower $f_{\mathrm{N}}$.) Interestingly, $J$ for samples with $f_{\mathrm{N}}=$ 0.36 and 0.48 are lower than those for samples with practically no water. This means that some regular local motion of the methylene and neighboring amide groups is stabilized by water, past a certain threshold value, in nylon 66 with any $f_{\mathrm{N}}$. On the other hand, the $\gamma$ peak does not seem to shift and its $J$ value does not change greatly, compared with the original samples, indicating that the $\gamma$ relaxation is independent of the water content, as has been pointed out previously. Note that $\alpha_{\rho}$ may also be shifted down to $c a$. 25$30{ }^{\circ} \mathrm{C}$.

Figure 3 shows typical thermal window spectra in the $\alpha$ and $\beta$ region for nylon 66 with lowest $f_{\mathrm{N}}$ as an example. Resolution into elementary peaks clearly shows the co-existence of elemental domains with different relaxation times. Mathematical analysis on each elementary peak, as described in analytical section, gives a $\ln \tau_{0}-E_{\mathrm{a}}$ plot and an Arrhenius type relation of $\log \tau$ vs. $1 / T$, as shown in Figure 4. Here, $\tau$ is the 


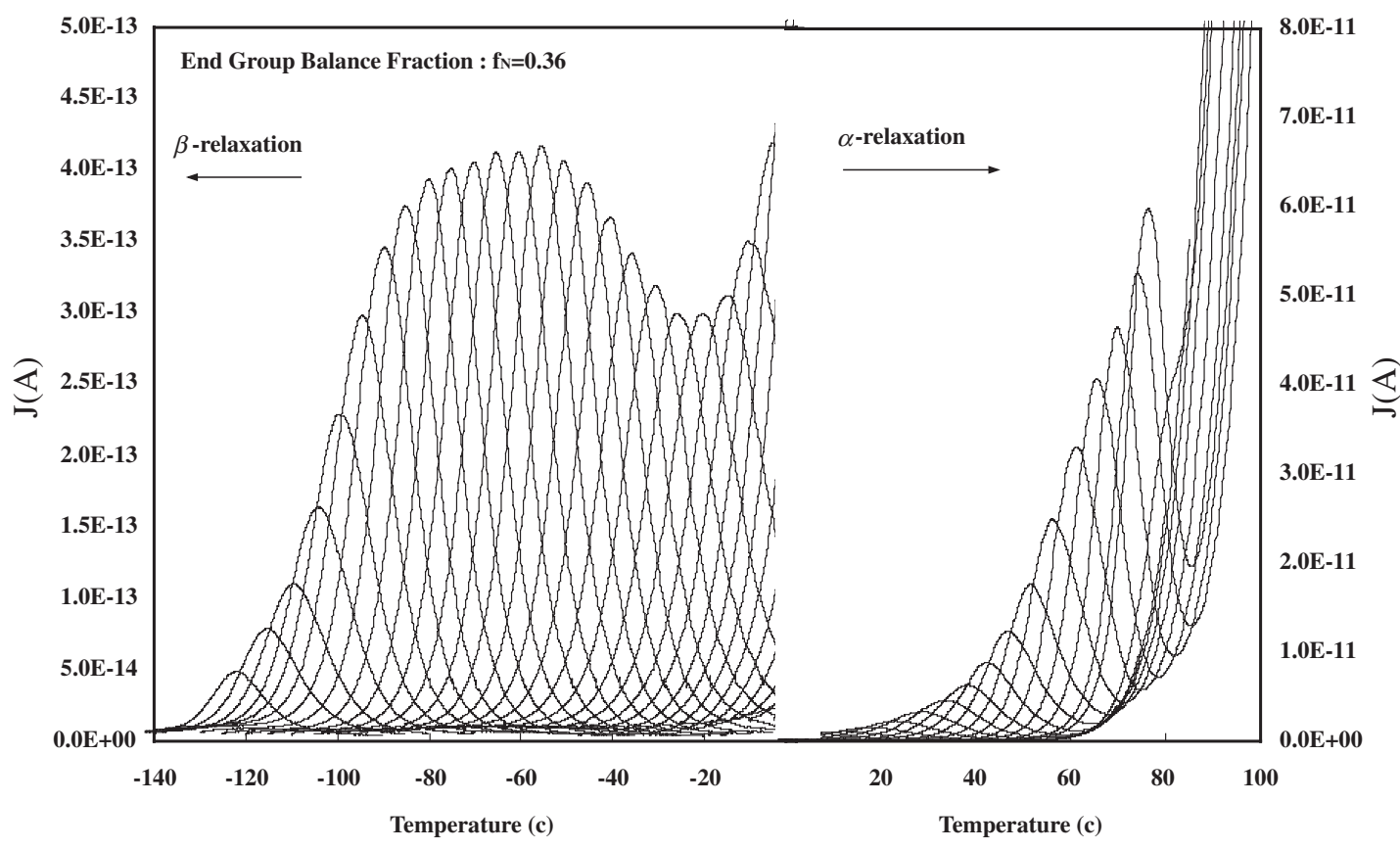

Figure 3. Typical thermal window spectra in $\alpha$ and $\beta$ relaxation regions for Nylon 66 with the lowest $f_{\mathrm{N}}$.

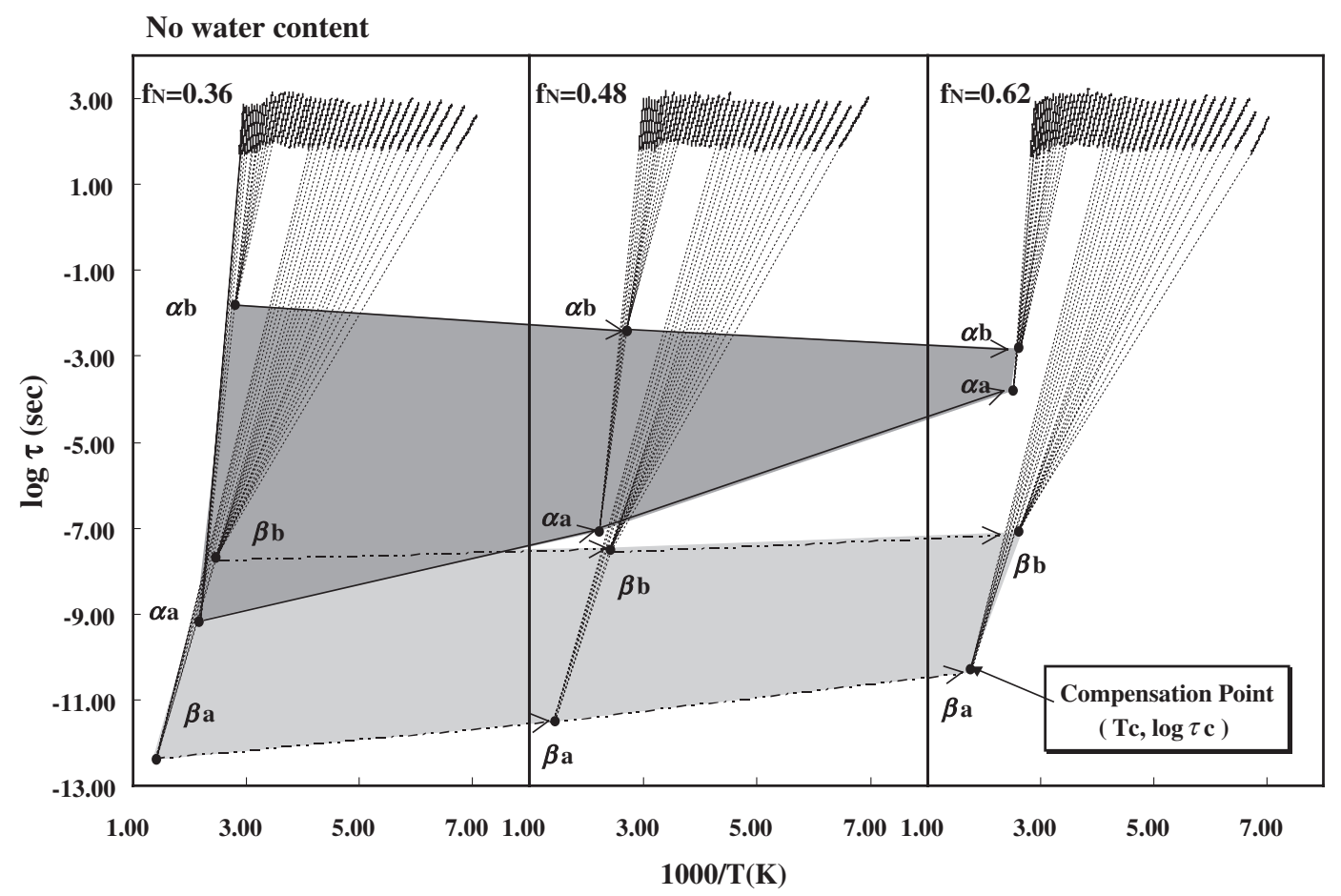

Figure 4. Dependence of relaxation time $\tau_{\mathrm{c}}$ on reciprocal of temperature.

relaxation time related to each elementary peak. The Arrhenius plot should be focused on a point, denoted as the compensation point, if the relaxation mechanism includes co-operation among the elementary relaxation units. Clearly, both the $\alpha$ and $\beta$ relaxations are composed of two segmental motions with different relaxation times, irrespective of the $f_{\mathrm{N}}$ of the polymers. These are denoted as $\alpha_{\mathrm{a}}, \alpha_{\mathrm{b}}$ and $\beta_{\mathrm{a}}, \beta_{\mathrm{b}}$, from the higher temperature side, respectively. However, the two segmental motions in each relaxation tend to merge into a unique relaxation mechanism as $f_{\mathrm{N}}$ of the polymers becomes large, and this tendency is stronger for the $\alpha$ relaxation. These results are also supported by the dielectric spectra with frequency dispersion, simulated according to the procedure described in the analytical section, as shown in Figure 5. Two peaks are distinctly observed for nylon 66 with lower $f_{\mathrm{N}}$ in both the $\alpha$ and $\beta$ relaxations. 

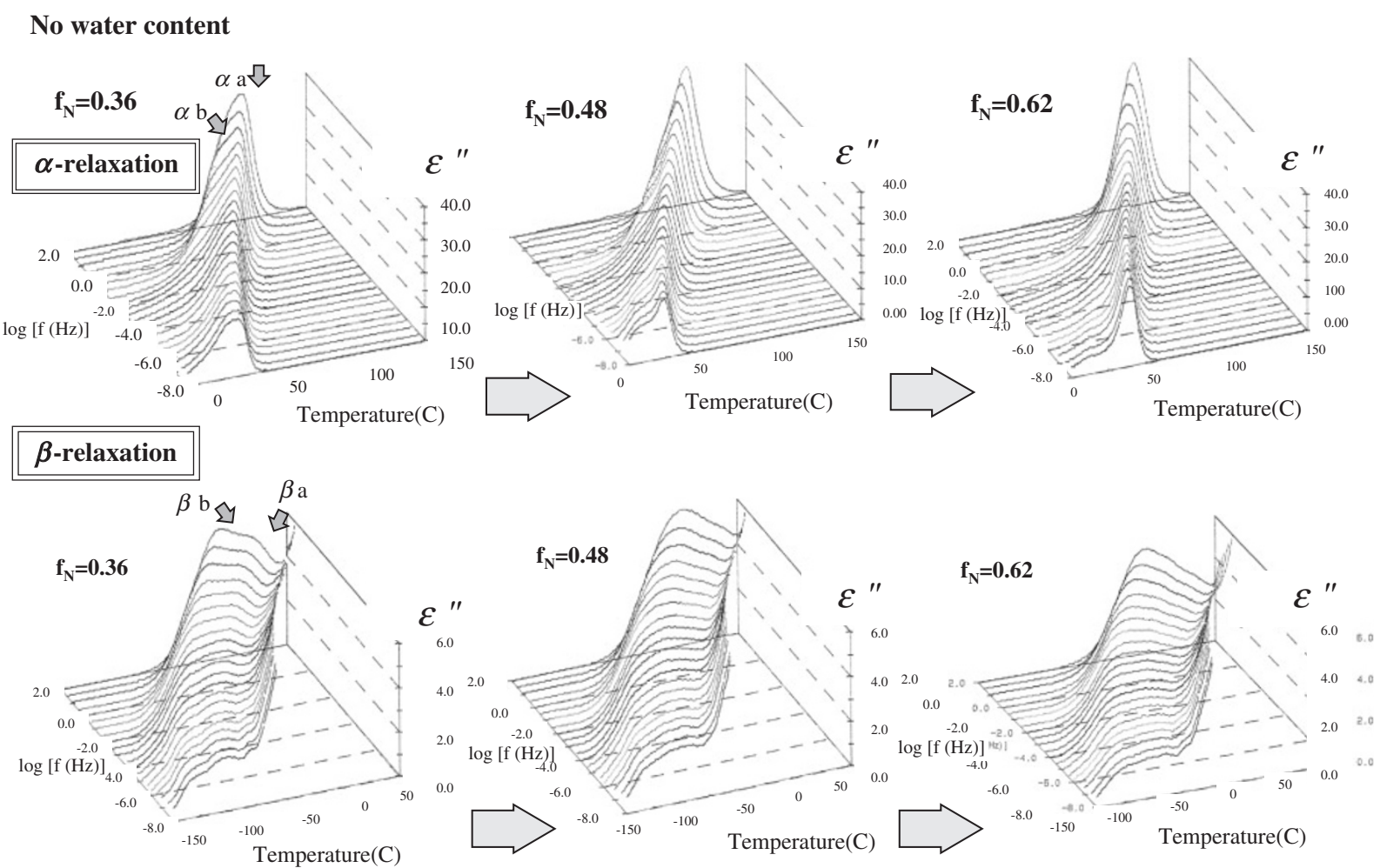

Figure 5. Simulated dielectric spectra with frequency dispersion for Nylon 66 having different $f_{\mathrm{N}}$ values.
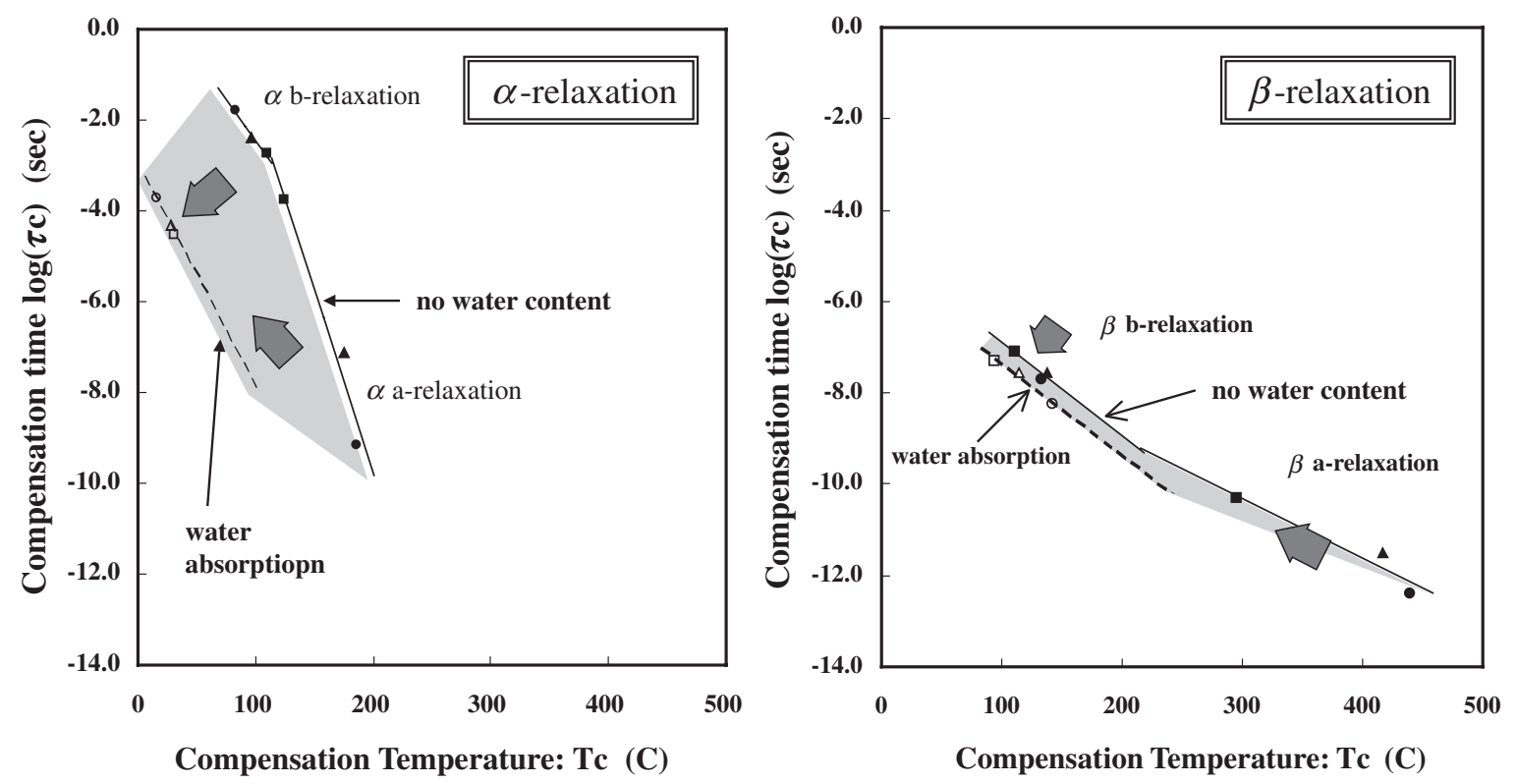

Figure 6. Relaxation mechanism of the cooperative chain motion by compensation law for $\alpha$ and $\beta$ relaxations: $\bullet, \bigcirc ; f_{\mathrm{N}}=0.36 \boldsymbol{\Delta}, \triangle$; $f_{\mathrm{N}}=0.48 \boldsymbol{\square}, \square ; f_{\mathrm{N}}=0.62$.

Thus, $\alpha$ and $\beta$ relaxations are composed of two segmental motions with different relaxation mechanisms. As mentioned before, these relaxations may be influenced by a very small amount of water in the polymer. The details of this effect are examined here. Figure 6 shows plots of compensation time $\tau_{\mathrm{c}} v s$. compensation temperature $T_{\mathrm{c}}$ before and after water absorption. Before water absorption, the $\tau_{\mathrm{c}}-T_{\mathrm{c}}$ relation correspond- ing to $\alpha_{\mathrm{a}}$ and $\alpha_{\mathrm{b}}$ or $\beta_{\mathrm{a}}$ and $\beta_{\mathrm{b}}$ evaluated for three nylon 66 samples give linear lines with different slopes, signifying that each relaxation is described by the same inherent mechanism, irrespective of the $f_{\mathrm{N}}$ of the samples. For both $\alpha$ and $\beta$ relaxations, water tends to merge the two mechanisms into one. More detailed consideration on the effect of water can be drawn from $\Delta S^{*}-\Delta H^{*}$ analysis before and after water ab- 


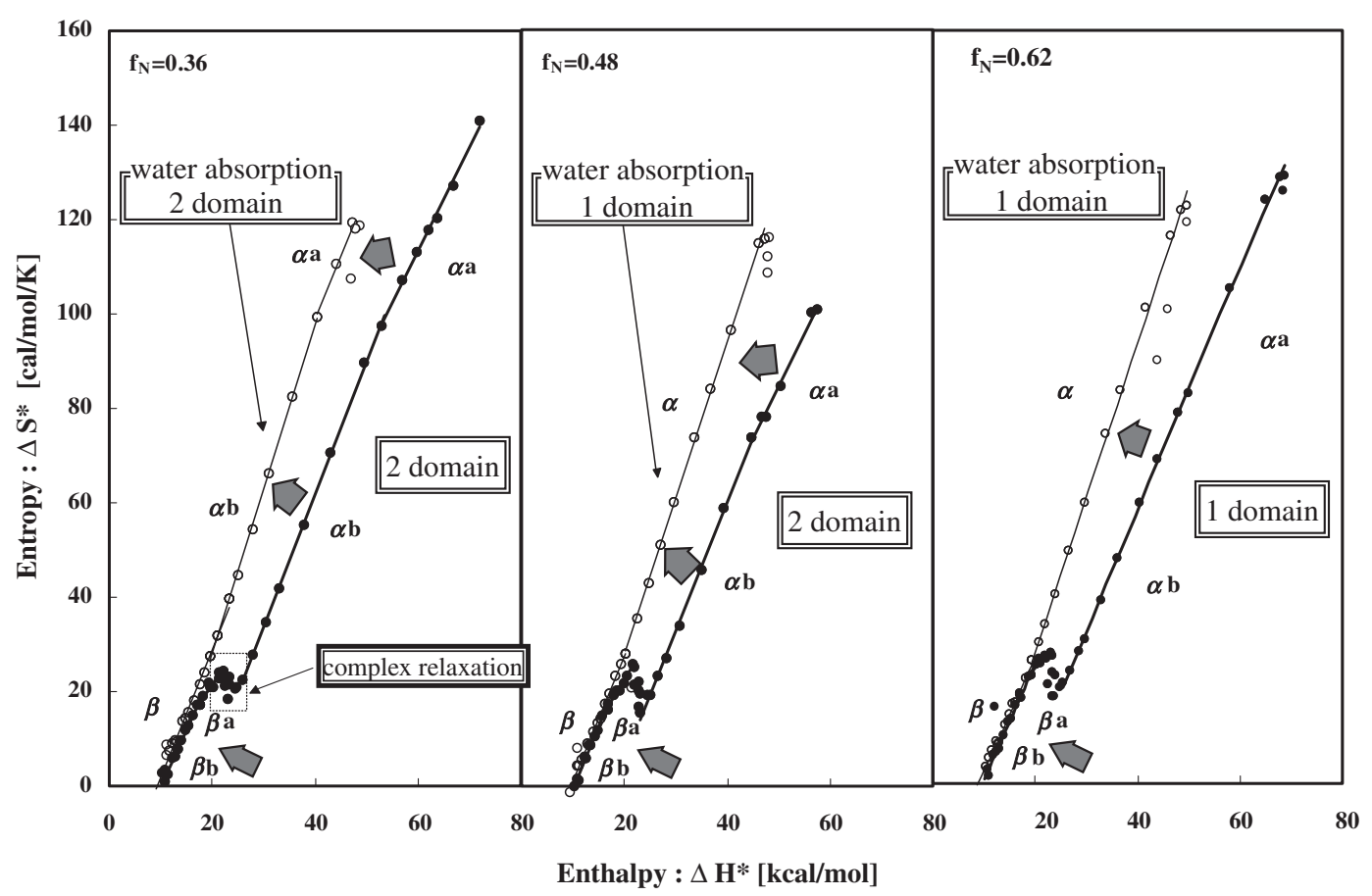

Figure 7. Variation in activation enthalpy $\Delta H^{*} v s$. activation entropy $\Delta S^{*}$ for each relaxation mode of Nylon 66 with different $f_{\mathrm{N}}$.

sorption, as shown in Figure 7. As shown above, $\alpha$ and $\beta$ relaxations are each composed of two segmental motions before water absorption, although this tendency is quite small for amino-rich nylon. Detailed inspection revealed that even after water absorption, the $\alpha$ relaxation of nylon 66 with the smallest $f_{\mathrm{N}}$ (carboxyl-rich nylon) still exhibited two segmental motions. This may be related to the fact that nylon 66 with the smallest $f_{\mathrm{N}}$ has two distinct $\alpha_{\rho}$ relaxations, as shown in Figure 1b.

\section{CONCLUSIONS}

We confirm through detailed TSDC analysis of nylon with different balance of end groups the existence of $\alpha_{\rho}, \alpha, \beta$ and $\gamma$ relaxations. The $\alpha_{\rho}$ relaxation which had previously been detected only as a strong upswing by mechanical relaxation analysis was well resolved with the discovery of two distinct relaxations for nylon rich in carboxyl end groups for the first time. $\alpha$ and $\beta$ relaxations were found to result from two different relaxation mechanisms. The former tend to merge into a single mechanism as $f_{\mathrm{N}}$ increases, and with the presence of water in the polymer, the two relaxation mechanisms also tend to merge into a single mechanism for both the $\alpha$ and $\beta$ relaxations. Even in the presence of water, $\alpha$ relaxation for nylon rich in carboxyl end groups still follows two different mechanisms. It was also confirmed by the study of the interaction of water with the polymer that the molecular chains in the amorphous region for nylon 66 rich in amino end groups show strong mutual interaction, hence exhibiting stability against water attack. Since polyamide has a plane-orientation structure similar to cellulose, there should exist a so-called hydrophobic plane along which a hydrophobic solvent, but not a hydrophilic solvent like water, might penetrate into the molecular aggregate, leading to some structural change. Results from this research support the utilization of nylon more effectively in the industrial field. But sufficient research has not yet been carried out. TSDC analysis is a most promising tool for clearly detecting structural changes caused by the introduction of a hydrophobic solvent into nylon 66.

\section{REFERENCES}

1. K. Schmieder and K. Wolf, Kolloid-Z., 134, 149 (1953).

2. C. W. Deeley, A. E. Woodward, and J. A. Sauer, J. Appl. Phys., 28, 1124 (1957).

3. J. Lacson, W. R. Dawson, and E. G. Bobalek, Preprints presented at 134th Meeting of ACS, Sept, 1958, Chicago, IL.

4. A. E. Woodward, J. A. Sauer, C. W. Deeley, and D. E. Kline, J. Colloid Sci., 12, 363 (1957).

5. A. E. Woodward, L. M. Crissmann, and J. A. Sauer, J. Polym. Sci., 4, 23 (1960).

6. T. Kawaguchi, J. Appl. Polym. Sci., 2, 56 (1959).

7. R. H. Boyel, J. Chem. Phys., 30, 1276 (1959).

8. K. H. Illers, Makromol. Chem., 38, 168 (1960).

9. J. Koarik and J. Janacek, Collect. Czech. Chem. Comun., 30, 2388 (1965).

10. W. Dahl and F. H. Muller, Z. Elektrochem., 65, 652 (1961).

11. M. Tuboi, Bull. Chem. Soc. Jpn., 25, 160 (1952).

12. H. W. Starkweather, J. Appl. Polym. Sci., 2, 129 (1959).

13. J. Koarik and J. Janacek, J. Polym. Sci., C, 16, 41 (1967). 
14. R. Puffr and J. Sebenda, J. Polym. Sci., C, 16, 79 (1967).

15. D. C. Prevorsek, R. H. Burler, and J. A. Reimschuesel, J. Polym. Sci., Part A-2: Polym. Phys., 9, 867 (1971).

16. S. Kapur, C. E. Rogers, and E. Baer, J. Polym. Sci., Polym. Phys. Ed., 2297 (1972).

17. P. Schiller, Z. Phys., 153, 1 (1958).

18. F. C. Magne, H. J. Portas, and H. Wakeham, J. Am. Chem. Soc., 69, 1896 (1947).

19. Y. S. Papir, S. Kapur, C. E. Rogers, and E. Baer, J. Polym. Sci., Part A-2: Polym. Phys., 10, 1305 (1972).

20. M. Tomokiyo, H. Yamazaki, F. Ise, M. Ohtsuka, T. Koizumi, and K. Okajima, Sen-i Gakkaishi, 53, 155 (1997).

21. M. Tomokiyo, Y. Furue, H. Yamazaki, M. Ohtsuka, and
K. Okajima, Sen-i Gakkaishi, to be submitted.

22. T. Koizumi, H. Ono, M. Tomokiyo, and K. Okajima, Polym. J., 28, 601 (1996).

23. J.-P. Crine, J. Appl. Phys., 66, 1308 (1989).

24. C. Bucci, R. Fieschi, and G. Guidi, Phys. Rev., 148, 816 (1966).

25. J. Vanderschueren and A. Linkens, Macromolecules, 11, 1228 (1978).

26. M. M. Perlman and S. Unger, J. Appl. Phys., 45, 2389 (1974).

27. C. Bucci and R. Fieschi, Phys. Rev. Lett., 12, 16 (1964).

28. S. Glasstone, K. J. Leider, and H. Eyring, "The Theory of Rate Processes,” McGraw-Hill, New York, N.Y., 1941. 